\title{
Article
}

\section{Pulmonary Delivery of Proteins Using Nanocomposite Microcarriers}

\author{
Alfagih, Iman, Kunda, Nitesh, Alanazi, Fares, Dennison, Sarah \\ Rachel, Somavarapu, Satyanarayana, Hutcheon, Gillian A. and \\ Saleem, Imran
}

Available at http://clok.uclan.ac.uk/19908/

Alfagih, Iman, Kunda, Nitesh, Alanazi, Fares, Dennison, Sarah Rachel ORCID: 0000-0003-4863-9607, Somavarapu, Satyanarayana, Hutcheon, Gillian A. and Saleem, Imran (2015) Pulmonary Delivery of Proteins Using Nanocomposite Microcarriers. Journal of Pharmaceutical Sciences, 104 (12). pp. 4386-4398. ISSN 0022-3549

It is advisable to refer to the publisher's version if you intend to cite from the work. http://dx.doi.org/10.1002/jps.24681

For more information about UCLan's research in this area go to http://www.uclan.ac.uk/researchgroups/ and search for <name of research Group>.

For information about Research generally at UCLan please go to http://www.uclan.ac.uk/research/

All outputs in CLoK are protected by Intellectual Property Rights law, including Copyright law. Copyright, IPR and Moral Rights for the works on this site are retained by the individual authors and/or other copyright owners. Terms and conditions for use of this material are defined in the policies page.

\section{CLoK}

Central Lancashire online Knowledge www.clok.uclan.ac.uk

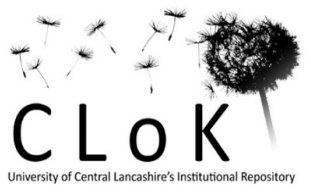


Please cite this article as: Kunda, Nitesh K., Alfagih, Iman M., Miyaji, Eliane N.,Figueiredo, Douglas B., Gonc,alves, Viviane M., Ferreira, Daniela M., Dennison, Sarah R., Somavarapu, Satyanarayana, Hutcheon, Gillian A., Saleem, Imran Y., Pulmonary Dry Powder Vaccine of Pneumococcal Antigen Loaded Nanoparticles.International Journal of Pharmaceutics http://dx.doi.org/10.1016/j.ijpharm.2015.09.034

\section{Pulmonary dry powder vaccine of pneumococcal antigen loaded nanoparticles}

Nitesh K Kunda ${ }^{a, b}$, Iman M Alfagih ${ }^{a, c}$, Eliane N Miyajid, Douglas B. Figueiredod, Viviane M Gonçalves ${ }^{\mathrm{d}}$, Daniela M Ferreira ${ }^{\mathrm{e}}$, Sarah R Dennison ${ }^{\mathrm{f}}$, Satyanarayana Somavarapug, Gillian A Hutcheon ${ }^{\mathrm{a}}$, Imran Y Saleem ${ }^{\mathrm{a}}$

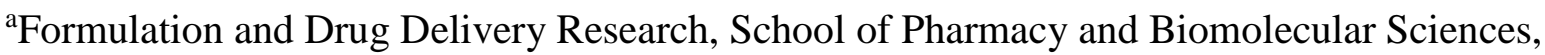
Liverpool John Moores University, Liverpool, UK;

${ }^{\mathrm{b}}$ Department of Pharmaceutical Sciences, College of Pharmacy, University of New Mexico, Albuquerque, USA;

cDepartment of Pharmaceutics, College of Pharmacy, King Saud University, Riyadh, Saudi Arabia;

${ }^{\mathrm{d}}$ Centro de Biotecnologia, Instituto Butantan, Sao Paulo, Sao Paulo, Brazil;

${ }^{\text {e}}$ Respiratory Infection Group, Liverpool School of Tropical Medicine, Liverpool, UK;

${ }^{f}$ UCLan Biomedical Research Facility, Research and Innovation, University of Central Lancashire, Preston, UK;

gDepartment of Pharmaceutics, School of Pharmacy, University College London, London, UK

Corresponding Author: *Formulation and Drug Delivery Research Group, School of Pharmacy and Biomolecular Sciences, Liverpool John Moores University, James Parson Building, Byrom Street, Liverpool L3 3AF, UK

Tel. No.: +44(0)1512312265

Fax. No.: +44(0)151231 2170 (FAO. Dr Imran Saleem)

E-mail: i.saleem@ljmu.ac.uk 


\begin{abstract}
Pneumonia, caused by Streptococcus pneumoniae, mainly affects the immunocompromised, the very young and the old, and remains one of the leading causes of death. A steady rise in disease numbers from non-vaccine serotypes necessitates a new vaccine formulation that ideally has better antigen stability and integrity, does not require cold-chain and can be delivered non-invasively. In this study, a dry powder vaccine containing an important antigen of S. pneumoniae, pneumococcal surface protein A (PspA) that has shown cross-reactivity amongst serotypes to be delivered via the pulmonary route has been formulated. The formulation contains the antigen PspA adsorbed onto the surface of polymeric nanoparticles encapsulated in L-leucine microparticles that can be loaded into capsules and delivered via an inhaler. We have successfully synthesized particles of $\sim 150 \mathrm{~nm}$ and achieved $\sim 20 \mu \mathrm{g}$ of PspA adsorption per $\mathrm{mg}$ of NPs. In addition, the spray-dried powders displayed a FPF of $74.31 \pm 1.32 \%$ and MMAD of $1.70 \pm 0.03 \mu \mathrm{m}$ suggesting a broncho-alveolar lung deposition facilitating the uptake of the nanoparticles by dendritic cells. Also, the PspA released from the dry powders maintained antigen stability (SDS-PAGE), integrity (Circular dichroism) and activity (lactoferrin binding assay). Moreover, the released antigen also maintained its antigenicity as determined by ELISA.
\end{abstract}

\title{
Graphical abstract
}
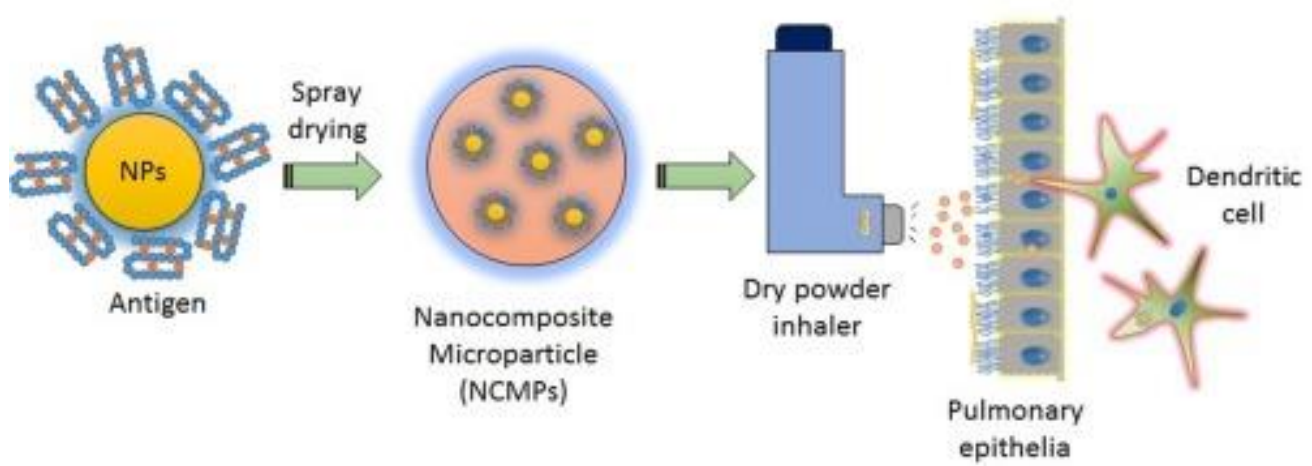


\section{Abbreviations}

$\mathrm{CD}$, Circular dichroism;

CLSM, confocal laser scanning microscopy;

ELISA, Enzyme-linked immunosorbent assay;

L-leu, L-leucine;

NGI, next generation impactor;

NPs, Nanoparticles;

NCMPs, Nanocomposite microparticles;

PGA-co-PDL, poly(glycerol adipate-co- $\omega$-pentadecalactone);

PspA4Pro, pneumococcal surface protein A;

PVA, polyvinyl alcohol;

$\mathrm{SD}$, spray-drying;

SDS-PAGE, Sodium Dodecyl Sulfate-Polyacrylamide Gel Electrophoresis

\section{Keywords}

Nanoparticle;

Dry powder inhalation;

Pneumococcal surface protein A (PspA);

Nanocomposite microcarrier;

Dendritic cells;

Antigen delivery system 
Please cite this article as: Kunda, Nitesh K., Alfagih, Iman M., Miyaji, Eliane N.,Figueiredo, Douglas B., Gonc,alves, Viviane M., Ferreira, Daniela M., Dennison, Sarah R., Somavarapu, Satyanarayana, Hutcheon, Gillian A., Saleem, Imran Y., Pulmonary Dry Powder Vaccine of Pneumococcal Antigen Loaded Nanoparticles.International Journal of Pharmaceutics http://dx.doi.org/10.1016/j.ijpharm.2015.09.034

\section{Introduction}

Pneumococcal diseases are infections caused by Streptococcus pneumoniae, also known as pneumococcus, which utilizes the respiratory tract as a portal of entry into the body. Pneumococcal diseases are classified into non-invasive pneumococcal diseases (otitis media, sinusitis, non-bacteremic pneumonia) or invasive pneumococcal diseases (IPD) (septicemia, meningitis, pneumonia) (Jambo et al., 2010). S. pneumoniae is the leading cause of bacterial pneumonia worldwide amongst the immunocompromised, the elderly, children under the age of 5, and adults in the developed world which is likely to increase with an aging population ( Wardlaw et al., 2006).

Currently, two pneumococcal vaccine types are available, polysaccharide vaccine (23-valent) and conjugate vaccine (10 or 13-valent) (Bogaert et al., 2004 and Wang and Curtiss III, 2014). The conjugate vaccines have shown higher efficacy for invasive infections compared to polysaccharide vaccines, but have lower levels of protection against mucosal diseases, such as pneumonia. Furthermore, these vaccines do not protect against non-vaccine serotypes, which has led to the emergence of diseases caused by these serotypes (Hicks et al., 2007 and Singleton et al., 2007). Moreover, conjugate vaccines are expensive, complicated and time consuming to manufacture thus limiting their usage especially in the low and middle income countries (LMICs) where a significant burden of the disease is reported (Walker et al., 2013). Consequently, with more than 90 serotypes identified and a steady rise in diseases by nonvaccine serotypes being reported, further emphasis on identifying and developing alternate vaccine candidates to be employed in an effective vaccine delivery system has gained importance (Miyaji et al., 2013).

Pneumococcal infections are mostly preceded by colonization of the upper airways and nasal carriage is a primary source of infection in humans (Kadioglu et al., 2008). Therefore, an optimal vaccination strategy would be to deliver the antigen via a mucosal route providing protection against both the colonizing bacteria and invasive disease. In addition, the activation of the immune system requires the effective delivery of antigen to antigen presenting cells (APCs) such as dendritic cells (DCs) which process the internalized antigen thereby generating an immune response ( Kwon et al., 2005).

Institutes such as US NIH and PATH have elaborated on the usage of pneumococcal proteins as alternate vaccine candidates for their ubiquitous presence across serotypes (Ginsburg et al., 2012). These proteins have the ability to protect against all serotypes thus preventing the prevalence of serotypes (Ginsburg et al., 2012 and Wang and Curtiss III, 2014). Among the different types of pneumococcal proteins such as pneumococcal surface protein A (PspA), pneumococcal surface protein $\mathrm{C}$ (PspC), pneumolysin; PspA is one of the most promising candidates and has been widely investigated by several groups (Briles et al., 2000a and Briles et al., 2000bHaughney et al., 2013, Moreno et al., 2010, Ogunniyi et al., 2007, Ogunniyi et al., 2001 and Vadesilho et al., 2012). The main function of PspA is preventing the deposition of complement on the surface of the bacterium thereby inhibiting opsonization and phagocytosis (Ren et al., 2004a and Ren et al., 2004b). PspA was also shown to inhibit death by apolactoferrin at mucosal sites (Shaper et al., 2004).

Vaccination with PspA has shown to induce protective antibodies in humans (Briles et al., $2000 \mathrm{~b}$ and Nabors et al., 2000). However, recombinant protein based vaccines can be poorly immunogenic generating low antibody responses in the absence of adjuvants or delivery 
Please cite this article as: Kunda, Nitesh K., Alfagih, Iman M., Miyaji, Eliane N.,Figueiredo, Douglas B., Gonc,alves, Viviane M., Ferreira, Daniela M., Dennison, Sarah R., Somavarapu, Satyanarayana, Hutcheon, Gillian A., Saleem, Imran Y., Pulmonary Dry Powder Vaccine of Pneumococcal Antigen Loaded Nanoparticles.International Journal of Pharmaceutics http://dx.doi.org/10.1016/j.ijpharm.2015.09.034

systems. Research is now focused on delivering antigens via particulate carriers where the antigen can be associated with the particles acting as delivery systems with the added benefit of augmenting the generated immune response upon uptake by APCs ( O’Hagan, 2001). In addition, particulate antigens are known to generate a stronger immune response compared to soluble antigen (Koppolu and Zaharoff, 2013). As such, research has been focused on using polymeric nanoparticles (NPs) as delivery vehicles for antigen delivery ( Kong et al., 2013 and Koppolu and Zaharoff, 2013). Lately, it has also been shown by different groups that polymeric particles have enhanced the immunogenicity of PspA ( Anish et al., 2014, Haughney et al., 2013 and Kong et al., 2013).

A dry powder vaccine delivered via the inhalation route can overcome certain challenges such as invasiveness, cold-chain requirements, low stability and integrity of the antigen that are often associated with the traditional liquid based vaccines currently available in the market ( Al-fagih et al., 2011, Blank et al., 2011 and Kunda et al., 2013). To address these issues in this study, a dry powder vaccine containing antigen adsorbed polymeric NPs for delivery via inhalation was successfully developed. Due to their low inertia, NPs are likely to be exhaled upon inhalation and thus have been encompassed in microparticles by spray-drying using L-leucine (L-leu) as a microcarrier (Kunda et al., 2015). Furthermore, the effect of the formulation process on the stability, integrity, antibody recognition and activity of PspA was investigated. In addition, NPs uptake by DCs was visualized.

\section{Materials and methods}

\subsection{Materials}

Acetonitrile (HPLC grade), glycerol, 3-(4,5-dimethylthiazol-2-yl)-2,5-diphenyl tetrazolium bromide (MTT), human lactoferrin, nile red dye (NR), phosphate buffered saline (PBS) tablets, poly(vinyl alcohol) (PVA, MW 9-10 KDa; 80\%), trifluoroacetic acid (TFA, HPLC grade), Tween $80^{\circledR}$ and antibiotic/antimycotic $(100 \mathrm{X})$ solution were obtained from Sigma-Aldrich, UK. L-leucine was purchased from BioUltra, Sigma, UK. Tissue culture flasks ( 25 and $\left.75 \mathrm{~cm}^{2}\right)$ with vented cap, 96-well flat bottom and U shaped plates, acetone, dimethyl sulfoxide (DMSO) and tetrahydrofuran were purchased from Fisher Scientific, UK. Alpha minimum essential medium ( $\alpha$-MEM) and granulocyte macrophage colony-stimulating factor (GM-CSF) was purchased from Life technologies, UK. Fetal calf serum (FCS) heat inactivated was purchased from Biosera UK. Micro BCA ${ }^{\mathrm{TM}}$ protein assay kit was purchased from Thermo Scientific, UK. Dendritic cell lines, JAWS II (CRL-11904 ${ }^{\mathrm{TM}}$ ) were purchased from American type culture collection (ATCC). The biodegradable polymer, poly(glycerol adipate-co- $\omega$ pentadecalactone), PGA-co-PDL was synthesized as described previously (Thompson et al., 2006).

\subsection{Preparation of nanoparticles and characterization}

The polymeric NPs were prepared using the synthesized polymer as previously described (Kunda et al., 2015). Briefly, $200 \mathrm{mg}$ of PGA-co-PDL was dissolved in $2 \mathrm{ml} \mathrm{DCM}$ and probe sonicated (20 $\mu \mathrm{m}$ amplitude) for $2 \mathrm{~min}$ under ice and upon addition to $5 \mathrm{ml}$ of $10 \% \mathrm{w} / \mathrm{v}$ PVA formed an emulsion. This was then added drop wise to $20 \mathrm{ml}$ of $0.75 \% \mathrm{w} / \mathrm{v}$ PVA under magnetic stirring at a speed of 500 RPM. The mixture was left stirring for $3 \mathrm{~h}$ at room 
Please cite this article as: Kunda, Nitesh K., Alfagih, Iman M., Miyaji, Eliane N.,Figueiredo, Douglas B., Gonc,alves, Viviane M., Ferreira, Daniela M., Dennison, Sarah R., Somavarapu, Satyanarayana, Hutcheon, Gillian A., Saleem, Imran Y., Pulmonary Dry Powder Vaccine of Pneumococcal Antigen Loaded Nanoparticles.International Journal of Pharmaceutics http://dx.doi.org/10.1016/j.ijpharm.2015.09.034

temperature to facilitate the evaporation of DCM. Nile Red, (NR) $0.5 \mathrm{mg}$ was added to the organic phase to prepare dye loaded NPs for characterization by confocal microscopy.

Particle size, poly dispersity index (PDI) and zeta-potential were measured by laser diffraction using a laser particle size analyzer (Zetasizer Nano ZS, Malvern Instruments Ltd., UK). For NP suspensions, an aliquot of $100 \mu \mathrm{l}$ was diluted with $5 \mathrm{ml}$ of deionized water and for NP suspensions with protein adsorption, $2 \mathrm{mg}$ of NPs were resuspended in $5 \mathrm{ml}$ of deionized water, loaded into a cuvette and the measurements were recorded at $25{ }^{\circ} \mathrm{C}(n=3)$.

\subsection{Production and purification of PspA4Pro}

The N-terminal $\alpha$-helix and the first block of the proline rich region of PspA from clade 4 (PspA4Pro), fragment with cross reactivity with PspA from other clades (Moreno et al., 2010), was cloned into $\mathrm{pET} 3 \mathrm{~b}^{+}$and expressed in Escherichia coli BL21 (DE3). The protein was produced and purified using previously published methods with slight modifications ( Carvalho et al., 2012, Horta et al., 2012 and Horta et al., 2014). The production of recombinant PspA4Pro was performed in 51 bioreactors using, fed-batch cultivation with defined medium containing glycerol as carbon source and lactose as inducer (Horta et al., 2012) or batch cultivation with complex medium containing glucose, glycerol and lactose for auto-induction (Horta et al., 2014). The purification method consisted of cell disruption in a continuous high pressure homogenizer, precipitation of the homogenate with cetyltrimethylammonium bromide, pellet removal by centrifugation, anion exchange chromatography in Q-Sepharose, cryoprecipitation and cation exchange chromatography in SP-Sepharose (Carvalho et al., 2012). The desired PspA4Pro purity (>95\%) and the developed process also removed lipopolysaccharide, yielding acceptable levels of endotoxin $(0.3-0.6 \mathrm{EU} / \mathrm{ml})$ in the final product (Brito and Singh, 2011).

\subsection{PspA4Pro adsorption and quantification}

NP suspensions were collected by centrifugation $\left(78,000 \mathrm{~g}, 40 \mathrm{~min}, 4{ }^{\circ} \mathrm{C}\right)$ and resuspended in $4 \mathrm{ml}$ of PspA4Pro at a ratio of 100:20 (NP:PspA4Pro). The mixture was left rotating on a HulaMixer ${ }^{\mathrm{TM}}$ Sample Mixer (Life Technologies, Invitrogen, UK) for $1 \mathrm{~h}$ at room temperature and 20 RPM. The PspA4Pro adsorbed NPs were then centrifuged, as above and the supernatant analyzed for protein content using a micro BCA protein assay kit. The amount of protein adsorbed in $\mu \mathrm{g}$ per mg of NPs $(n=3)$ was calculated using Eq. (1):

$$
\text { Adsorption }(\mu \text { gpermgofNPs })=\frac{\text { (Initial proteinconcentration }- \text { Superna tan tproteinconcentration })}{\text { Amount of NPs }}
$$

The particle size, PDI and zeta-potential of NPs with and without PspA4Pro adsorption were measured as above.

\subsection{Preparation and characterization of nanocomposite microparticles}


Please cite this article as: Kunda, Nitesh K., Alfagih, Iman M., Miyaji, Eliane N.,Figueiredo, Douglas B., Gonc,alves, Viviane M., Ferreira, Daniela M., Dennison, Sarah R., Somavarapu, Satyanarayana, Hutcheon, Gillian A., Saleem, Imran Y., Pulmonary Dry Powder Vaccine of Pneumococcal Antigen Loaded Nanoparticles.International Journal of Pharmaceutics http://dx.doi.org/10.1016/j.ijpharm.2015.09.034

Nanocomposite microparticles (NCMPs) incorporating PspA4Pro adsorbed NPs were prepared by spray-drying using a Büchi B-290 mini spray-dryer (Büchi Labortechnik, Flawil, Switzerland) with a nozzle atomizer diameter of $0.7 \mathrm{~mm}$ and fitted with a high-performance cyclone. The NPs were suspended in L-leu solution at a NPs-to-carrier ratio of 1:1.5 w/w and spray-dried at a feed rate of $10 \%$ with an atomizing air flow of $400 \mathrm{~L} / \mathrm{h}$, aspirator capacity of $100 \%$ and an inlet temperature of $100{ }^{\circ} \mathrm{C}$ (outlet temperature of $45-47^{\circ} \mathrm{C}$ ). The dry particles were collected and stored in a desiccator at room temperature until further use. The resultant NCMPs were characterized as follows:

Yield: the dry powder yield\% (w/w) was determined as the difference in the weight of the sample vial before and after product collection compared to the initial total dry mass $(n=3)$.

Morphology: spray-dried PspA4Pro adsorbed NPs/NCMPs were mounted on aluminum pin stubs $(13 \mathrm{~mm})$ layered with a sticky conductive carbon tab and coated with palladium (10$15 \mathrm{~nm}$ ) using a sputter coater (EmiTech K 550X Gold Sputter Coater, $25 \mathrm{~mA}, 3 \mathrm{~min}$ ), and visualized using scanning electron microscopy (FEI Quanta ${ }^{\mathrm{TM}} 200$ ESEM, Holland).

\subsection{In vitro release studies}

The in vitro release studies were performed by adding $20 \mathrm{mg}$ of PspA4Pro adsorbed NPs/NCMPs into Eppendorf's and then dispersed in $2 \mathrm{ml}$ of PBS, $\mathrm{pH}$ 7.4. The samples were incubated at $37^{\circ} \mathrm{C}$ and left rotating for $48 \mathrm{~h}$ at $20 \mathrm{RPM}$ on a HulaMixer ${ }^{\mathrm{TM}}$ Sample Mixer (Life Technologies, Invitrogen, UK). At pre-determined time intervals up to $48 \mathrm{~h}$, the samples were centrifuged (accuSpin Micro 17, Fisher Scientific, UK) at 17,000 g for $30 \mathrm{~min}$ and $1 \mathrm{ml}$ of the supernatant removed and replaced with fresh medium. The supernatant was analyzed using the HPLC method as mentioned below. Each experiment was repeated in triplicate and the result was the mean value of three different samples $(n=3)$. The percentage cumulative protein released was calculated using Eq. (2):

$\%$ Cumulative protein released $=\frac{\text { Cumulative protein released }}{\text { Protein loaded }} \times 100$

\subsection{High performance liquid chromatography method}

A HPLC method was developed to quantify the amount of protein, PspA4Pro, present in a given sample. The optimum chromatographic conditions employed were as follows: HPLC system Agilent 1100 series (Santa Clara, CA, USA) equipped with a column (Aeris $3.6 \mu \mathrm{m} \mathrm{C4}$ 200A Wide Pore $4.6 \mathrm{~mm}$ i.d. $\times 150 \mathrm{~mm}$ length), security cartridge of the same material (Phenomenex, UK) and software for data processing, mobile phase was composed of (A) $0.1 \%$ w/v TFA in water and (B) 0.1\% w/v TFA in acetonitrile with a gradient flow of A/B from 80:20 to $35: 65$ in $25 \mathrm{~min}$, post-time $6 \mathrm{~min}$, flow rate of $0.8 \mathrm{ml} / \mathrm{min}$, injection volume of $100 \mu \mathrm{l}$, run temperature $40{ }^{\circ} \mathrm{C}$, UV detection at $214 \mathrm{~nm}$ and pspA4Pro retention time of $14.9 \mathrm{~min}$. The protein calibration curve was prepared from stock solution $(1 \mathrm{mg} / \mathrm{ml})$ in HPLC water and PBS (pH 7.4) to obtain the following concentrations: $0.5,1,2.5,5,10,25,50,100$ and $200 \mu \mathrm{g} / \mathrm{ml}$ of protein $\left(n=9, R^{2}=0.999\right)$. 
Please cite this article as: Kunda, Nitesh K., Alfagih, Iman M., Miyaji, Eliane N.,Figueiredo, Douglas B., Gonc,alves, Viviane M., Ferreira, Daniela M., Dennison, Sarah R., Somavarapu, Satyanarayana, Hutcheon, Gillian A., Saleem, Imran Y., Pulmonary Dry Powder Vaccine of Pneumococcal Antigen Loaded Nanoparticles.International Journal of Pharmaceutics http://dx.doi.org/10.1016/j.ijpharm.2015.09.034

\subsection{Investigation of PspA4Pro structure and activity}

\subsubsection{Sodium dodecyl sulfate-polyacrylamide gel electrophoresis (SDS-PAGE)}

The primary structure of PspA4Pro released from the NPs/NCMPs after spray-drying was determined by SDS-PAGE. A 9\% stacking gel (Geneflow Limited, UK) containing 0.4\% SDS and protein loading buffer blue $(2 \mathrm{X})$ was added to the samples in a 1:1 (v/v) buffer-to-sample ratio. Samples were loaded $(25 \mu \mathrm{l}$ per well) and the gel was run for $2.5 \mathrm{~h}$ at a voltage of $100 \mathrm{~V}$ with Tris-glycine-SDS PAGE buffer (10X). The gel was stained with colloidal coomassie blue and left overnight in distilled water for destaining and imaged using a gel scanner (GS-700 Imaging Densitometer, Bio-Rad) equipped with Quantity One software.

\subsubsection{Circular dichroism (CD)}

The secondary structure of the released PspA4Pro was determined by CD spectroscopy using a J-815 spectropolarimeter (Jasco, UK) at $20^{\circ} \mathrm{C}$ as previously described (Kunda et al., 2015). A $10 \mathrm{~mm}$ path-length cell was used to perform five scans per sample at a scan speed of $50 \mathrm{~nm} / \mathrm{min}$ over wavelength $260-180 \mathrm{~nm}$ at a data pitch of $0.5 \mathrm{~nm}$ and band width of $1 \mathrm{~nm}$. The baseline acquired in the absence of samples was subtracted (Henzler Wildman et al., 2003) and the secondary structure of the samples was estimated using the CDSSTR method (reference protein dataset 3) from the DichroWeb server (Whitmore et al., 2010).

\subsubsection{Antibody recognition test of PspA4Pro integrity}

The protein integrity was determined by antibody recognition using Enzyme-linked immunosorbent assay (ELISA) as previously described by Haughney et al. (2013) with slight modifications. Briefly, released PspA4Pro $(50 \mu \mathrm{l}, 0.5 \mu \mathrm{g} / \mathrm{ml})$ was coated on a high binding 96well plate (Costar 96-Well Microplates, Cole-Parmer, UK) followed by incubation overnight at $4{ }^{\circ} \mathrm{C}$. The PspA4Pro solution was removed from the wells and blocking buffer, PBS with $1 \%$ fish gelatin (Sigma-Aldrich, UK), was added and incubated for $2 \mathrm{~h}$ at room temperature. After incubation, the buffer was removed and the wells were washed with PBS containing $0.5 \%$ Tween 20 (PBS-T) (3×). The anti-PspA monoclonal antibody 22,003 (QED Bioscience, San Diego, CA) $(100 \mu \mathrm{l}, 1 \mu \mathrm{g} / \mathrm{ml})$ was added to each well and incubated overnight at $4{ }^{\circ} \mathrm{C}$. The plates were then washed with PBS-T $(3 \times)$ followed by addition of alkaline phosphataseconjugated goat anti-mouse IgG (Jackson ImmunoResearch Europe Ltd., UK) $(100 \mu$, $0.1 \mu \mathrm{g} / \mathrm{ml})$. The plates were incubated for $2 \mathrm{~h}$ at room temperature and $200 \mu \mathrm{l}$ of alkaline phosphatase yellow (pNPP) liquid substrate buffer (Sigma-Aldrich, UK) was added and incubated for $15 \mathrm{~min}$ at room temperature to develop the ELISA. The colorimetric changes were measured at $405 \mathrm{~nm}$ using a microplate reader (Epoch, BioTek Instruments Ltd., UK). The ratio of absorbance between the released PspA4Pro and the native protein was represented as relative antibody recognition. 
Please cite this article as: Kunda, Nitesh K., Alfagih, Iman M., Miyaji, Eliane N.,Figueiredo, Douglas B., Gonc,alves, Viviane M., Ferreira, Daniela M., Dennison, Sarah R., Somavarapu, Satyanarayana, Hutcheon, Gillian A., Saleem, Imran Y., Pulmonary Dry Powder Vaccine of Pneumococcal Antigen Loaded Nanoparticles.International Journal of Pharmaceutics http://dx.doi.org/10.1016/j.ijpharm.2015.09.034

\subsubsection{Lactoferrin binding}

$5 \mathrm{mg}$ of PspA4Pro adsorbed NPs/NCMPs NP/NCMPs were incubated for $4 \mathrm{~h}$ in $500 \mu \mathrm{lBS}$ $\mathrm{pH} 7.4$ at $37{ }^{\circ} \mathrm{C}$ with shaking. Samples were centrifuged at $15,700 \mathrm{~g}$ for $15 \mathrm{~min}$, from which $30 \mu$ of the supernatant was loaded onto a SDS-PAGE gel and samples were transferred to a nitrocellulose membrane, which was incubated with biotin-labeled lactoferrin (Human lactoferrin labeled with biotin using a Biotin Labeling Kit (Roche Life Sciences)). Lactoferrin binding was evaluated by incubation with streptavidin-HRP (BD Biosciences) and detection using Amersham ECL Prime Western Blot Detection Reagent (GE Healthcare).

\subsection{Cell viability study}

$100 \mu \mathrm{l}$ DCs were seeded $\left(2.5 \times 10^{5}\right.$ cells $\left./ \mathrm{ml}\right)$ with complete medium $(\alpha$-MEM containing ribonucleosides, deoxyribonucleosides, $4 \mathrm{mM}$ L-glutamine, $1 \mathrm{mM}$ sodium pyruvate supplemented with $20 \%$ FCS, $5 \mathrm{ng} / \mathrm{ml}$ murine GM-CSF and $1 \%$ antibiotic/antimycotic solution) in 96-well plates incubated at $37{ }^{\circ} \mathrm{C}, 5 \% \mathrm{CO}_{2}$ for $4 \mathrm{~h} .100 \mu \mathrm{l}$ empty NPs dispersions in complete medium were added at concentration $(0-2.5 \mathrm{mg} / \mathrm{ml})(n=3)$, and $10 \%$ dimethyl sulfoxide (DMSO) as a positive control. The formulations were assayed for toxicity over $4 \mathrm{~h}$ incubation at $37{ }^{\circ} \mathrm{C}$, followed by the addition of MTT $(40 \mu \mathrm{l}, 5 \mathrm{mg} / \mathrm{ml})$ for $2 \mathrm{~h}$. The complete medium was removed and replaced with DMSO $(100 \mu \mathrm{l})$ in order to dissolve the formazan crystals. The absorbance was measured at $570 \mathrm{~nm}$ using a plate reader (Molecular Devices, SpectraMAX 190), and the percentage of viable cells was calculated as the absorbance ratio between NPs-treated and untreated control cells.

\subsection{Cellular uptake of NPs by DCs}

The uptake of NPs by DCs in cell culture medium and PBS were visualized using the confocal laser scanning microscopy (CLSM) (Carl Zeiss LSM 710, UK). The DCs $\left(2 \times 10^{5}\right.$ cells per well) were seeded onto an 8-well chambered \#1 borosilicate coverglass system (Nunc LabTek, Thermo Scientific, UK) and incubated at $37{ }^{\circ} \mathrm{C}$ for $48 \mathrm{~h}$. NPs at concentrations of 2.5$5 \mu \mathrm{g} / \mathrm{ml}$ were incubated for $1 \mathrm{~h}$ at $37{ }^{\circ} \mathrm{C}$ with DCs. Following this, the supernatant was removed, washed three times with PBS and the DCs were fixed with $4 \%$ paraformaldehyde (Fisher Scientific, UK) for $10 \mathrm{~min}$ at room temperature. The DCs were then washed three times with PBS and $100 \mu \mathrm{l}$ of $5 \mu \mathrm{g} / \mathrm{ml}$ wheat germ agglutinin antibody (WGA, Alexa Fluor ${ }^{\circledR}$ 488Conjugate, Life Technologies, UK) was added and incubated at $37^{\circ} \mathrm{C}$ for $15 \mathrm{~min}$. The excess antibody was removed by washing three times with PBS followed by staining the nucleus of DCs with $100 \mu \mathrm{l}$ of $20 \mu \mathrm{g} / \mathrm{ml} \mathrm{4',6-diamidino-2-phenylindole,} \mathrm{dilactate} \mathrm{(DAPI,}$ Sigma-Aldrich, UK), and then incubated for $10 \mathrm{~min}$ at room temperature. Excess DAPI was removed by washing three times with PBS.

\subsection{In vitro aerosolization studies}


PspA4Pro adsorbed NPs/NCMPs were weighed into capsules (Hypromellose, HPMC, capsule, size 3, each corresponding to $12.5 \mathrm{mg}$ spray-dried powder and equivalent to $5 \mathrm{mg}$ of NPs) and placed in a Cyclohaler ${ }^{\circledast}$ (Teva Pharmaceutical Industries Ltd.). A pump (Copley Scientific, Nottingham, UK) operated at a flow rate of $60 \mathrm{~L} / \mathrm{min}$ for $4 \mathrm{~s}$ (corresponding to $4 \mathrm{KPa}$ pressure drop across the inhaler) drew samples through the next generation impactor (NGI, Copley Scientific, Nottingham, UK). Samples were collected from the NGI using distilled water and left on a roller-shaker for $48 \mathrm{~h}$ for the PspA4Pro to be released from the NCMPs and then centrifuged using an ultracentrifuge. The supernatant was analyzed using HPLC method. The percentage deposition (\%) of protein was calculated as the percentage ratio of protein amount collected in each stage to that of total amount of protein collected in all stages. The fine particle fraction (FPF, \%) was determined as the fraction of emitted dose deposited in the NGI with $\mathrm{d}_{\mathrm{ae}}<4.46 \mu \mathrm{m}$, the mass median aerodynamic diameter (MMAD, $\left.\mu \mathrm{m}\right)$ was calculated from logprobability analysis, and the fine particle dose (FPD, $\mu \mathrm{g})$ was expressed as the mass of drug deposited in the NGI with $\mathrm{d}_{\mathrm{ae}}<4.46 \mu \mathrm{m}(n=3)$ in one actuation.

\subsection{Statistical analysis}

One-way analysis of variance (ANOVA) with Tukey's comparison using Minitab $^{\circledR} 17$ Statistical Software was employed for comparing the formulations, with statistical significant differences determined as $p<0.05$. All values are expressed as mean \pm standard deviation.

\section{Results}

\subsection{PspA4Pro adsorption and quantification}

The average adsorption of PspA4Pro onto NPs was $19.68 \pm 2.74 \mu \mathrm{g}$ per mg of NPs. Table 1 lists the particle size, PDI and zeta-potential of PGA-co-PDL NPs with and without PspA4Pro adsorption. The significant increase in particle size $(p<0.05)$ of NPs accompanied with a change in the surface charge can be ascribed to the adsorption of PspA4Pro onto NPs. 
Please cite this article as: Kunda, Nitesh K., Alfagih, Iman M., Miyaji, Eliane N.,Figueiredo, Douglas B., Gonc salves, Viviane M., Ferreira, Daniela M., Dennison, Sarah R., Somavarapu, Satyanarayana, Hutcheon, Gillian A., Saleem, Imran Y., Pulmonary Dry Powder Vaccine of Pneumococcal Antigen Loaded Nanoparticles.International Journal of Pharmaceutics http://dx.doi.org/10.1016/j.ijpharm.2015.09.034

Table 1. Particle size, PDI and zeta-potential of PGA-co-PDL nanoparticles (NPs) with and without pneumococcal surface protein $\mathrm{A}(\mathrm{PspA4Pro})$ adsorption (mean $\pm \mathrm{SD}, n=3$ ).

\begin{tabular}{llc} 
& Without adsorption & With adsorption \\
\hline Particle Size $(\mathrm{nm})$ & $203.90 \pm 2.55^{\mathrm{a}^{*}}$ & $322.83 \pm 04.25^{\mathrm{b}^{*}}$ \\
PDI & $0.205 \pm 0.007$ & $0.402 \pm 0.018$ \\
Zeta-potential $(\mathrm{mV})$ & $-24.56 \pm 0.50$ & $-13.23 \pm 0.11$
\end{tabular}

aNPs characterised after centrifugation.

bNPs characterised after centrifugation.

${ }^{*} p<0.05$, ANOVA/Tukey's.

\subsection{Characterization of nanocomposite microparticles}

\subsubsection{Yield, particle size and morphology}

A reasonable yield of spray-dried NCMPs was obtained, with $55.55 \pm 6.64 \%$ for the PspA4Pro adsorbed NPs/NCMPs. The SEM pictures (Fig. 1) of blank NPs/NCMPs revealed the shape to be irregular with a corrugated surface texture. The size of NCMPs calculated from SEM pictures was approximately $1.99 \pm 0.25 \mu \mathrm{m}$.
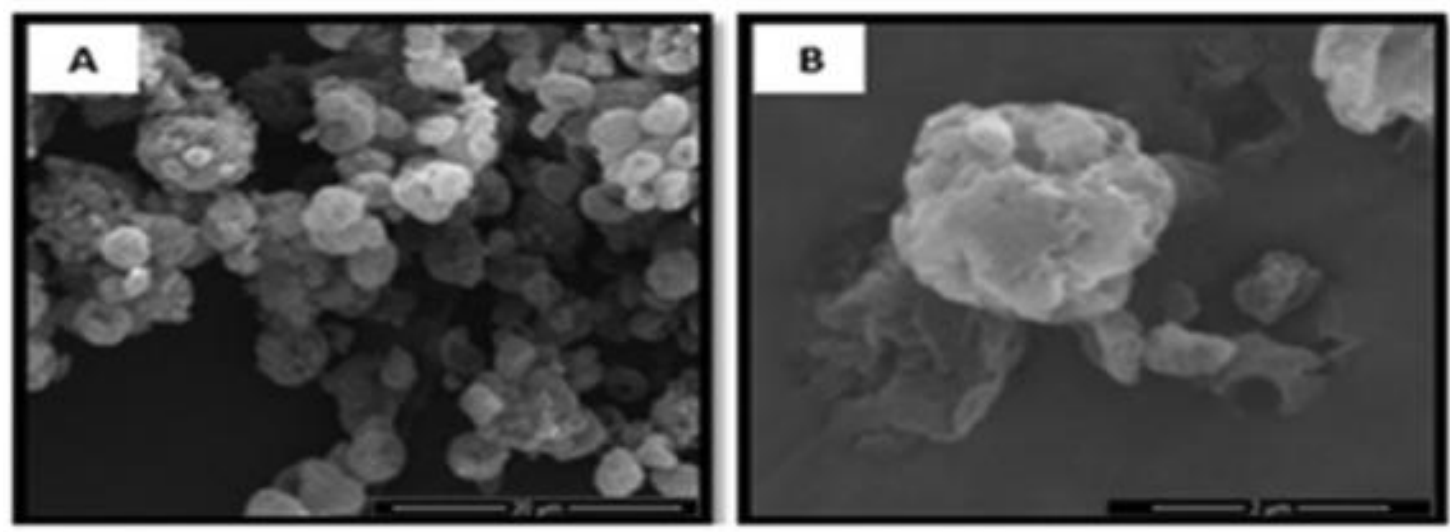

Fig. 1. SEM pictures of spraydried NPs/NCMPs. Scale bar (A) $20 \mu \mathrm{m}$ and (B) $2 \mu \mathrm{m}$. 


\subsubsection{In vitro release studies}

The cumulative percentage of PspA4Pro released over time from NPs/NCMPs (Fig. 2), indicated an initial burst release of $40.59 \pm 4.94 \%$ was observed followed by continuous release of $89.81 \pm 2.95 \%$ up to $5 \mathrm{~h}$, eventually reaching $94.30 \pm 2.90 \%$ over $48 \mathrm{~h}$.

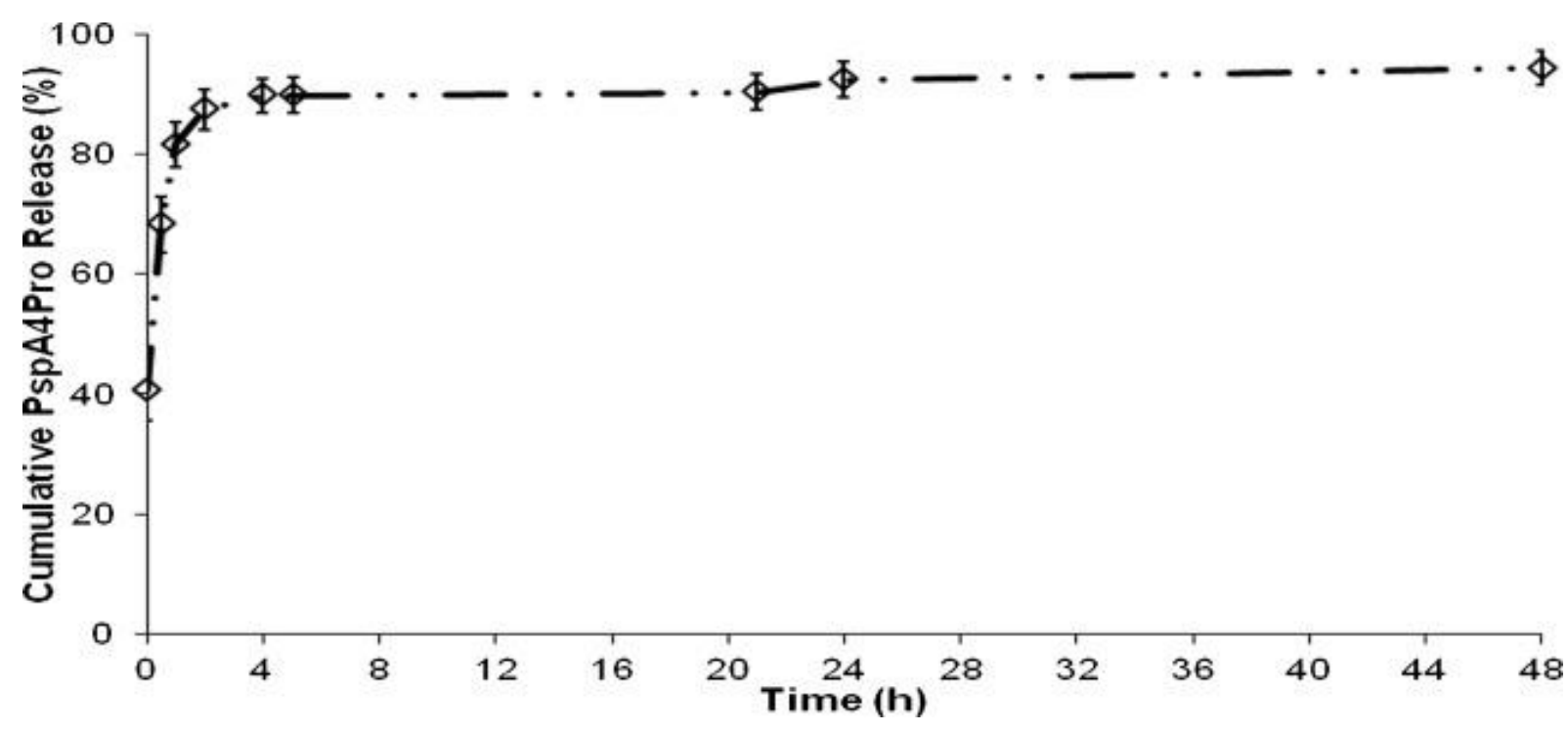

Fig. 2. In vitro release of pneumococcal surface protein A (PspA4Pro) from NPs/NCMPs in phosphate buffer saline, $\mathrm{pH} 7.4$ (mean $\pm \mathrm{SD}, n=3$ ).

\subsubsection{In vitro aerosolization studies}

The deposition data obtained displayed a FPD of $60.02 \pm 8.56 \mu \mathrm{g}$ (per capsule of $12.5 \mathrm{mg}$ ), FPF of $74.31 \pm 1.32 \%$ and MMAD of $1.70 \pm 0.03 \mu \mathrm{m}$ suggesting that the formulation was capable of delivering efficient PspA4Pro to the bronchial-alveolar region of the lungs. Fig. 3 shows the percentage stage-wise deposition of PspA4Pro in NGI. 
Please cite this article as: Kunda, Nitesh K., Alfagih, Iman M., Miyaji, Eliane N.,Figueiredo, Douglas B., Gonc,alves, Viviane M., Ferreira, Daniela M., Dennison, Sarah R., Somavarapu, Satyanarayana, Hutcheon, Gillian A., Saleem, Imran Y., Pulmonary Dry Powder Vaccine of Pneumococcal Antigen Loaded Nanoparticles.International Journal of Pharmaceutics http://dx.doi.org/10.1016/j.ijpharm.2015.09.034

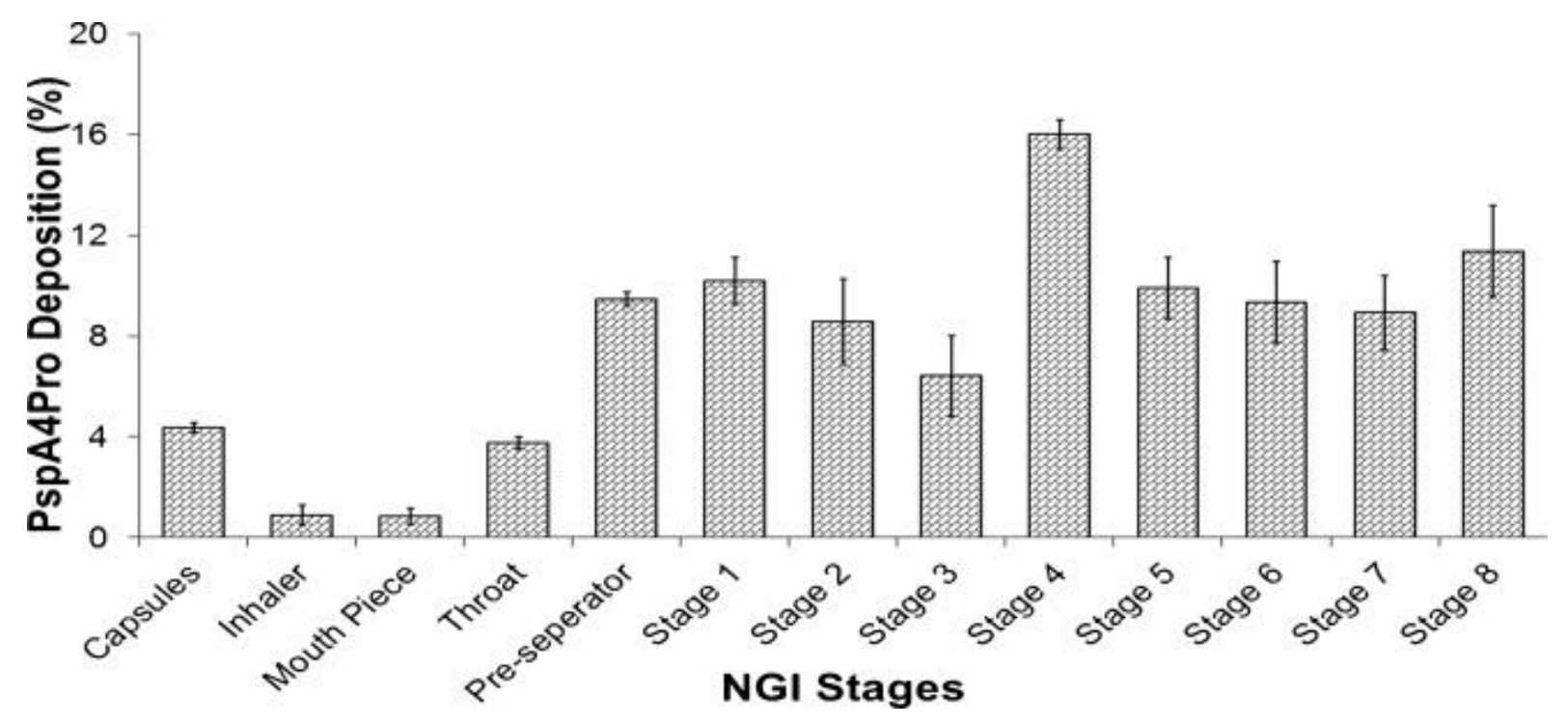

Fig. 3. The percentage deposition of pneumococcal surface protein A (PspA4Pro) stage-wise in next generation impactor (NGI) (mean $\pm \mathrm{SD}, n=3$ ).

\subsection{Investigation of PspA4Pro structure}

The PspA4Pro released from the NPs/NCMPs was analyzed for primary and secondary structure using SDS-PAGE and CD, respectively. Fig. 4(a) indicates that the PspA4Pro released from NPs/NCMPs remained intact, based on the presence of a single band between 43 and $66 \mathrm{KDa}$, and no other bands of either small or large MW were visible indicating no degradation or aggregation, respectively.

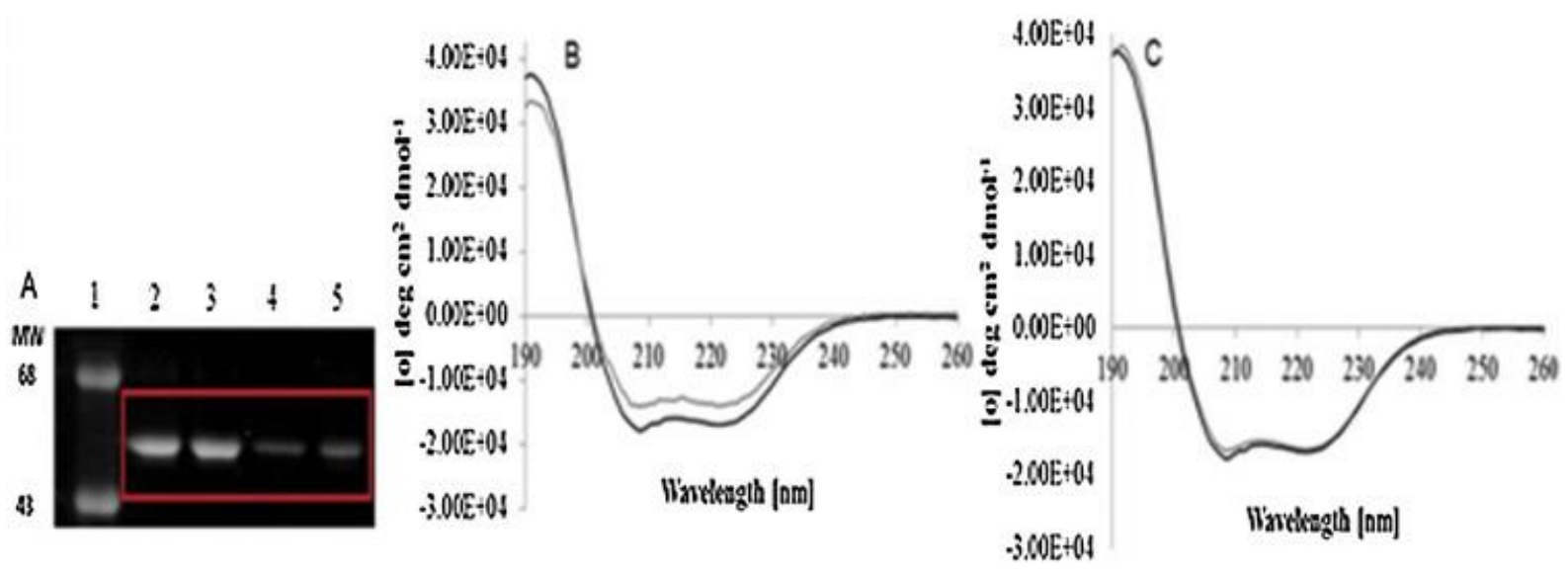

Fig. 4. (A) SDS-PAGE of Lane 1: MW standards, broad range (Bio-Rad Laboratories; Hercules CA, USA), Lane $2 \&$ 3: pneumococcal surface protein A (PspA4Pro) standard, Lane 4 \& 5: Released PspA4Pro from NPs/NCMPs after $48 \mathrm{~h}$. Circular Dichroism (CD) spectra of pneumococcal surface protein A (PspA4Pro) standard (black) from: (B) adsorbed PGA-coPDL NPs, supernatant (grey) and (C) PGA-co-PDL NPs/NCMPs, released (grey). 
The conformational changes of PspA4Pro released from the NPs/NCMPs and PspA4Pro supernatant after adsorption onto NPs and centrifugation were investigated by CD spectroscopy. Fig. 4(b and c) represents the CD spectra of standard PspA4Pro, PspA4Pro supernatant, and PspA4Pro released from the NPs/NCMPs. The spectra indicate two characteristic minima at 208 and $222 \mathrm{~nm}$, known to be associated with $\alpha$-helical structure. The data for the spectra presented in Table 2 for standard PspA4Pro, PspA4Pro supernatant and PspA4Pro released, indicated that the predominant structure of the protein was helical displaying 64.5, 64 and 51\% helicity, respectively. Hence, the $\alpha$-helical content of PspA4Pro released when compared to the standard, decreased by $13.5 \%$.

Table 2. The percentages of secondary structures of standard, supernatant and released pneumococcal surface protein A (PspA4Pro) samples.

\begin{tabular}{lllll}
\hline Sample & Helix & Strand & Turns & Unordered \\
\hline Standard PspA4Pro & $64.50 \pm 0.02$ & $06.00 \pm 0.00$ & $07.50 \pm 0.00$ & $22.00 \pm 0.01$ \\
PspA4Pro Supernatant & $64.00 \pm 0.02$ & $07.00 \pm 0.01$ & $08.00 \pm 0.01$ & $20.50 \pm 0.01$ \\
PspA4Pro Released & $51.00 \pm 0.03$ & $21.00 \pm 0.01$ & $07.50 \pm 0.01$ & $20.00 \pm 0.03$
\end{tabular}

\subsection{Antibody recognition test of PspA4Pro integrity and lactoferrin binding}

The antibody recognition of released PspA4Pro from NPs/NCMPs was determined using ELISA with a specific anti-PspA monoclonal antibody and represented as relative antibody recognition. The assay measures the ability of released PspA4Pro to bind and be recognized by an anti-PspA antibody. Fig. 5(a) shows that the PspA4Pro released from the NCMPs maintained its integrity with relative antibody recognition of $0.97 \pm 0.20$ compared to PspA4Pro standard. To analyze the maintenance of important functional epitopes in the PspA4Pro released from NPs/NCMPs, the binding of PspA4Pro to lactoferrin was investigated. As shown in Fig. 5(b), PspA4Pro recovered from the NPs/NCMPs (lane 1) was able to bind to lactoferrin, indicating that the lactoferrin-binding site is intact in the sample. Lanes 2 and 3 show the binding of lactoferrin to control standard PspA4Pro. 
Please cite this article as: Kunda, Nitesh K., Alfagih, Iman M., Miyaji, Eliane N.,Figueiredo, Douglas B., Gonc,alves, Viviane M., Ferreira, Daniela M., Dennison, Sarah R., Somavarapu, Satyanarayana, Hutcheon, Gillian A., Saleem, Imran Y., Pulmonary Dry Powder Vaccine of Pneumococcal Antigen Loaded Nanoparticles.International Journal of Pharmaceutics http://dx.doi.org/10.1016/j.ijpharm.2015.09.034
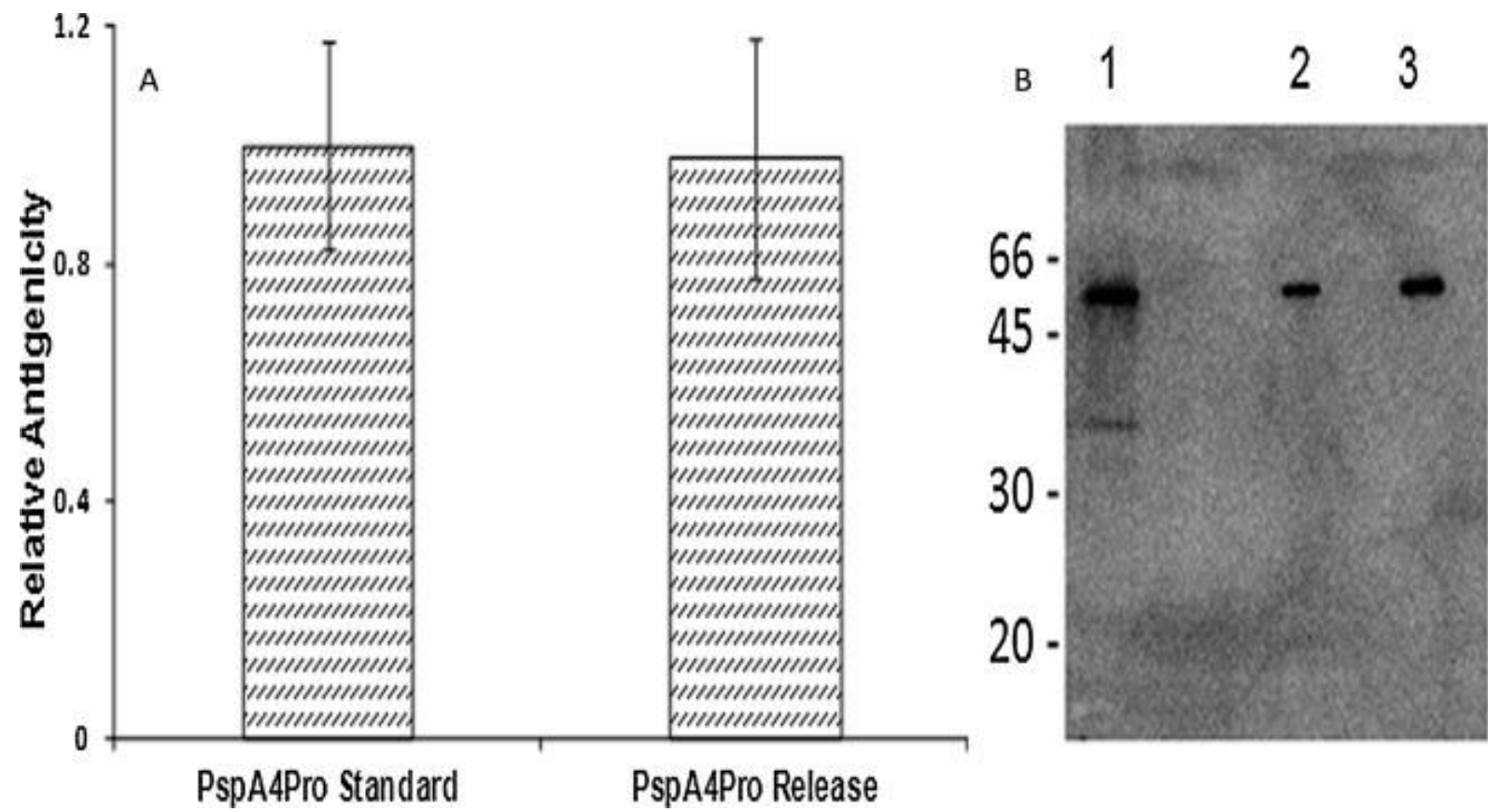

Fig. 5. (A) Antibody recognition of pneumococcal surface protein A (PspA4Pro) upon release from NPs/NCMPs, (B) Lactoferrin binding of released PspA4Pro from NPs/NCMPs. Lane 1: PspA4Pro released from NCMPs, Lane 2 \& 3: PspA4Pro standard at $100 \mathrm{ng}$ and $25 \mathrm{ng}$ respectively.

\subsection{Cell viability study \& cellular uptake of NPs by DCs}

The toxicity of non-loaded PGA-co-PDL NPs following $4 \mathrm{~h}$ incubation using a DC cell line, were assessed by the MTT assay. The NPs (Fig. 6) showed increased cell death with an increase in NPs concentration. The NPs showed up to $90 \%$ cell viability at $19.53 \mu \mathrm{g} / \mathrm{ml}$ concentration that reduced to $\sim 55 \%$ at $1.25 \mathrm{mg} / \mathrm{ml}$ concentration. The uptake of NR/NPs by DCs was observed using confocal microscopy. The cell wall of the DCs (stained with WGA Alexa Fluor ${ }^{\circledast}$ 488), the nucleus (stained with DAPI) and the NPs (containing Nile Red) were observed under the green, blue and red channel, respectively. Fig. 7 shows the split view of DCs incubated with NR/NPs for $1 \mathrm{~h}$ in cell culture medium and PBS buffer, respectively. In addition, the orthogonal view NR/NPs uptake in cell culture medium and PBS buffer can be seen in Fig. 8 . 
Please cite this article as: Kunda, Nitesh K., Alfagih, Iman M., Miyaji, Eliane N.,Figueiredo, Douglas B., Gonc,alves, Viviane M., Ferreira, Daniela M., Dennison, Sarah R., Somavarapu, Satyanarayana, Hutcheon, Gillian A., Saleem, Imran Y., Pulmonary Dry Powder Vaccine of Pneumococcal Antigen Loaded Nanoparticles.International Journal of Pharmaceutics http://dx.doi.org/10.1016/j.ijpharm.2015.09.034

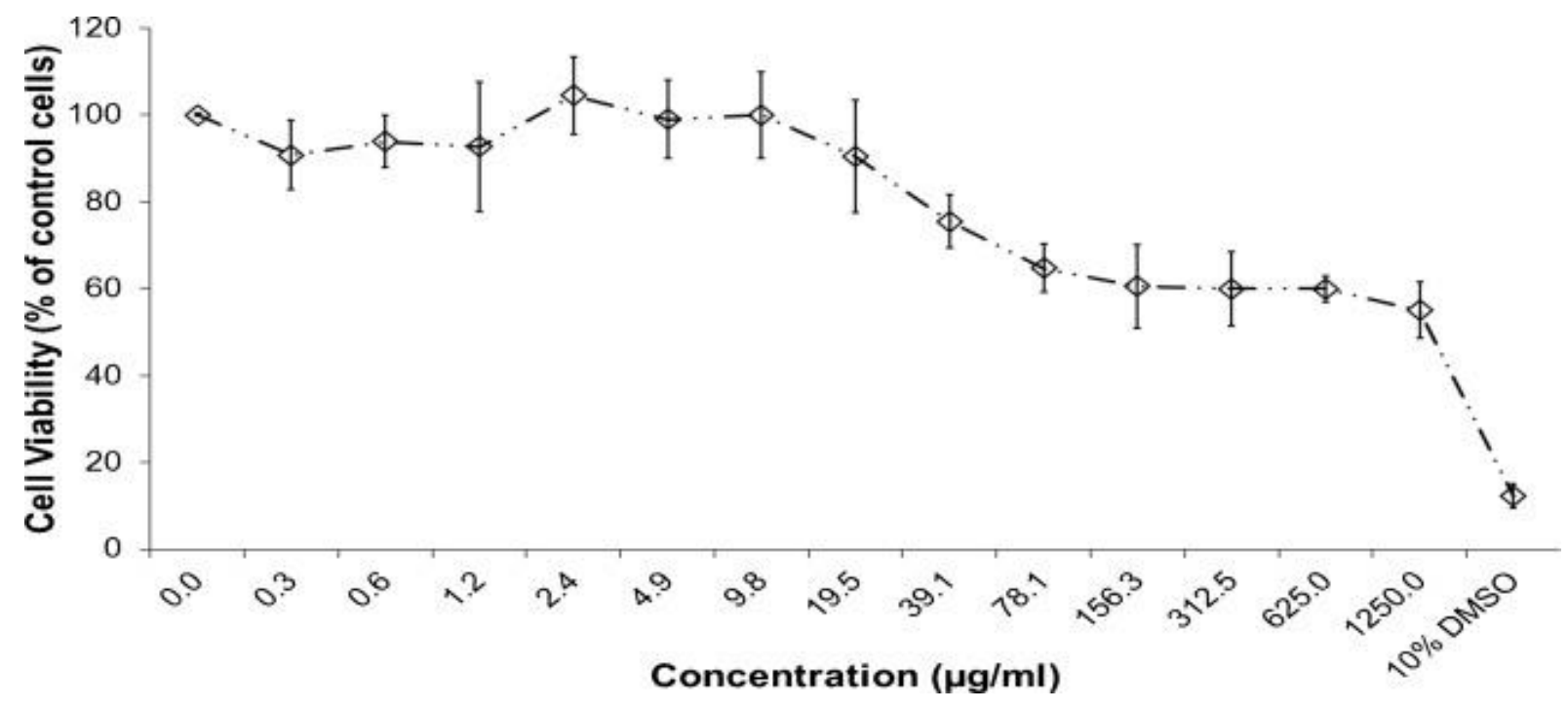

Fig. 6. Dendritic Cells (DCs) cell viability measured by MTT assay after 4 h exposure to PGAco-PDL nanoparticles (NPs) (mean $\pm \mathrm{SD}, \mathrm{n}=3$ ).
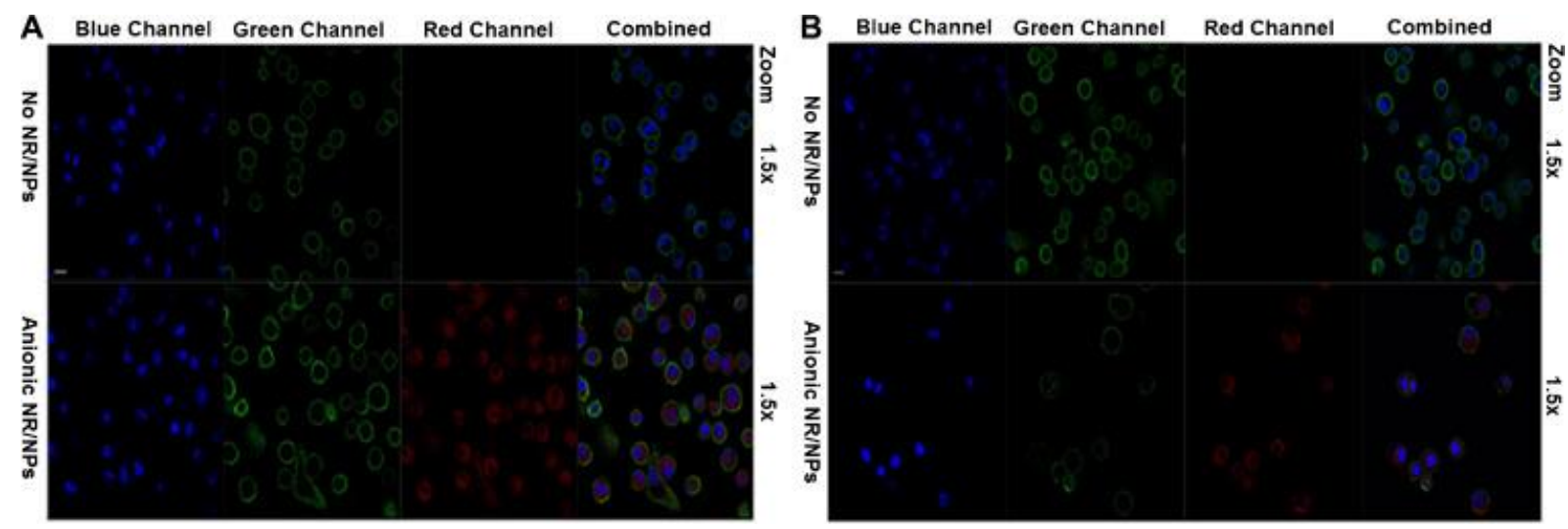

Fig. 7. Confocal microscopic images depicting a split view of dendritic cells (DCs) (40X lens) incubated in the absence and presence of Nile Red (NR)/nanoparticles (NPs) in (A) cell culture medium or (B) phosphate buffer saline (PBS) for $1 \mathrm{~h}$ (Scale bar-20 $\mu \mathrm{m})$.

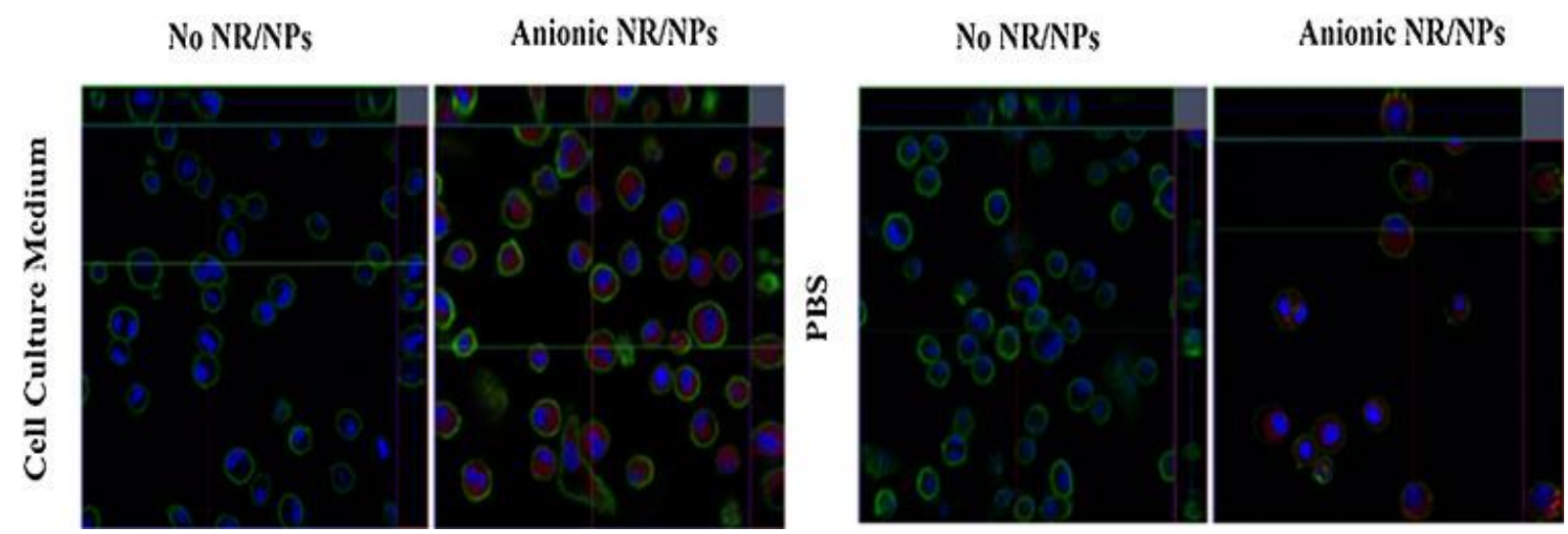

Fig. 8. Confocal microscopic images depicting an orthogonal view of DCs (40X lens) incubated in the absence and presence of Nile Red (NR)/nanoparticles (NPs) in cell culture medium and phosphate buffer saline (PBS) for $1 \mathrm{~h}$. 


\section{Discussion}

Here, we utilized the optimum conditions from our previous study, of model protein adsorption onto polymeric particles (Kunda et al., 2015), for PspA4Pro adsorption onto PGA-co-PDL NPs. We spraydried PspA4Pro adsorbed NPs producing NCMPs to develop a pneumococcal protein vaccine against S. pneumoniae to be delivered via dry powder inhalation. Additionally, we investigated the antigen stability and integrity in the final formulation.

Approximately $20 \mu \mathrm{g}$ of PspA4Pro was adsorbed per mg of PGA-co-PDL NPs. The adsorption achieved with PspA4Pro was almost twice that of bovine serum albumin (BSA, $10 \mu \mathrm{g}$ per mg of NPs) as reported by Kunda et al. (2015). This could be related to the MW of PspA4Pro ( 43-50 KDa) being smaller than BSA ( $\sim 66 \mathrm{KDa}$ ) thus providing more space on the NPs for PspA4Pro to adsorb. In addition, the elongated structure of PspA4Pro could enable the accommodation of more protein molecules on the surface of the NPs (Stolnik et al., 2001).

PspA has both negative and positive ends, however, in distilled water $(\mathrm{pH} \sim 7)$ the protein carries a net negative charge as the $\mathrm{pH}$ is greater than the $\mathrm{pI}$ of PspA (4.82). The adsorption process was performed in distilled water, and at this $\mathrm{pH}$, the protein was negatively charged and hydrophobic interactions and hydrogen bonding would be the dominant forces of adsorption onto the NPs, which had a negative zeta potential. Adsorption of PspA4Pro onto the surface of the NPs led to an increase in the hydrodynamic diameter as evident from the increase in particle size. In addition, the decrease in surface charge could be due to the protein molecules orientation adopted on the surface of the NPs exposing only a small part of the protein. Similar results have been reported by Koppolu and Zaharoff (2013) and Gordon et al. (2008).

The PspA4Pro adsorbed NPs were spray-dried into NCMPs using l-leu as a microcarrier, displaying a rough and wrinkled surface texture. This has been widely reported in the literature, together with benefits for dry powder aerosolization (Seville et al., 2007, Sou et al., 2013, Tawfeek et al., 2011 and Tawfeek et al., 2013). The FPF $(\sim 74 \%)$ and MMAD $(\sim 1.7 \mu \mathrm{m})$ obtained for the PspA4Pro adsorbed NPs/NCMPs suggest an excellent aerosolization performance similar to that observed for BSA adsorbed NPs/NCMPs (FPF: 77 \% and MMAD: $1.21 \mu \mathrm{m}$ ) (Kunda et al., 2015).

The in vitro release data from PspA4Pro adsorbed NPs/NCMPs indicated a burst release of $40 \%$ with complete release ( $\sim 94 \%)$ within $48 \mathrm{~h}$. Though a high burst release was observed, this would not be a limiting factor for vaccination because any antigen released can still be taken up by DCs for processing and presentation, and that which is adsorbed onto NPs (intact) can also be taken up potentially giving an adjuvant effect as reported by Ghotbi et al. (2011), Cruz et al. (2012) and others ( Carrillo-Conde et al., 2011, Cruz et al., 2012 and Ghotbi et al., 2011). Further, it has been established that for NPs to act as an immune potentiator or adjuvant, the attachment of NPs and antigen may not be mandatory; hence, the particles without antigen adsorbed can be taken up by DCs enhancing the immune response (Zhao et al., 2014). Moreover, studies in the literature have reported the uptake of particles by DCs within 1$2 \mathrm{~h}$ of incubation ( Cruz et al., 2012, Karagouni et al., 2013 and Saleem et al., 2005). 
Please cite this article as: Kunda, Nitesh K., Alfagih, Iman M., Miyaji, Eliane N.,Figueiredo, Douglas B., Gonc,alves, Viviane M., Ferreira, Daniela M., Dennison, Sarah R., Somavarapu, Satyanarayana, Hutcheon, Gillian A., Saleem, Imran Y., Pulmonary Dry Powder Vaccine of Pneumococcal Antigen Loaded Nanoparticles.International Journal of Pharmaceutics http://dx.doi.org/10.1016/j.ijpharm.2015.09.034

The structure of PspA4Pro released from NPs/NCMPs was investigated using SDS-PAGE (primary structure) and CD (secondary structure). The SDS-PAGE of PspA4Pro released from the formulations confirmed that the protein had not degraded based on the presence of a single band. This shows that the protein remained intact during the adsorption, spray-drying process and desorption. In addition, the CD spectral data obtained for the released PspA4Pro confirmed the presence of $\alpha$-helix and $\beta$-sheets. However, there is a decrease in the helical content observed $(\sim 13 \%)$. This effect could be due to the adsorption and desorption process or spray-drying. However, the antigenicity of released PspA4Pro showed the ability to effectively recognize and bind to the anti-PspA monoclonal antibody. Furthermore, the lactoferrin-binding site of PspA4Pro is functional after release from the NPs/NCMPs. This suggests that despite the reduction of $\alpha$-helix structure the functional part of the antigen is still active. The results obtained with SDS-PAGE, CD antibody recognition and lactoferrin binding provides an indication that PspA delivered via NPs/NCMPs is stable and retains antigenicity for generating an immune response.

PspA administered nasally (through a mucosal site) with an adjuvant into mice, a dose of only $100 \mathrm{ng}$ was required to generate an immune response equivalent to that elicited by oral administration of $7.5 \mu \mathrm{g}$ (Yamamoto et al., 1998). Considering that the NCMPs produced here are to be administered via inhalation i.e. through a mucosal site, the dose required would be $\sim 100 \mathrm{ng}$ of PspA for mice, requiring NCMPs concentrations lower than $20 \mu \mathrm{g} / \mathrm{ml}$. However, the dose of PspA4Pro would be different for human immunization via the pulmonary route (yet to be determined). In addition, it has been shown that the clinical dose required for pneumococcal polysaccharide vaccine administered via nebulized inhalation is estimated to be about $25 \mu \mathrm{g}$ ( Menzel et al., 2005 and Meyer et al., 2006). Furthermore, intramuscular administration of rPspA achieved antibody responses at $25 \mu \mathrm{g}$ (Nabors et al., 2000). Although the mechanisms of immune response between polysaccharide and PspA are different; if we assume a similar dose is required for dry powder pulmonary delivery, then using PGA-co-PDL NPs/NCMPs we are able to deliver $60.02 \pm 8.56$ ug of PspA (FPD per capsule of $12.5 \mathrm{mg}$ ). Hence, we can adjust the amount of spray-dried powder to approximately $5.21 \mathrm{mg}$ to achieve the relevant $25 \mu \mathrm{g}$ dose.

It has now become evident that particulate antigens provide a Th1 type immune response (Couvreur and Vauthier, 2006, Gamvrellis et al., 2004 and Joshi et al., 2013). In addition, the size, charge, shape and site of delivery all affect the extent of DCs uptake and thus the immune response generated (Joshi et al., 2013), with NPs $<500 \mathrm{~nm}$ showing higher uptake and activation of DCs and inducing stronger immune responses (Foged et al., 2005, Joshi et al., 2013 and Koppolu and Zaharoff, 2013). Here, to substantiate our claims of effective uptake by DCs upon producing NPs of size $\sim 300 \mathrm{~nm}$, their uptake in JAWS II DC cell type was visualized using confocal microscopy. In cell culture media, NR fluorescence was detected when PGA-co-PDL NR/NPs were co-incubated with DCs for $1 \mathrm{~h}$ indicating the presence of NR/NPs within the DCs. However, Xu et al. (2009) have recently observed that NR, a lipophilic dye often used to stain intercellular lipid bodies, was released in the presence of cell culture medium and/or transferred directly to the cell membrane of contacting cells. It was also observed that the release of NR was significantly impeded in PBS. To investigate if the red fluorescence signals seen within the DCs is indeed the NR/NPs or the released NR, the uptake studies were repeated by coincubating the NR/NPs with DCs in PBS medium. The presence of the red fluorescence was evident for PGA-co-PDL NR/NPs confirming their internalization by DCs thereby effectively endorsing the suitability of the size of NPs produced for vaccine delivery. 
Please cite this article as: Kunda, Nitesh K., Alfagih, Iman M., Miyaji, Eliane N.,Figueiredo, Douglas B., Gonc,alves, Viviane M., Ferreira, Daniela M., Dennison, Sarah R., Somavarapu, Satyanarayana, Hutcheon, Gillian A., Saleem, Imran Y., Pulmonary Dry Powder Vaccine of Pneumococcal Antigen Loaded Nanoparticles.International Journal of Pharmaceutics http://dx.doi.org/10.1016/j.ijpharm.2015.09.034

\section{Conclusion}

The results obtained above show that PspA4pro can effectively be adsorbed onto PGA-co-PDL NPs ( $20 \mu \mathrm{g}$ of PspA4Pro per mg of NPs). The stability (primary and secondary structure) of the released PspA4Pro was maintained and relative antigenicity has been retained. Moreover, the functional part of the antigen was active in the formulation as determined by lactoferrin binding. In addition, the aerosol properties (FPF of $74.31 \pm 1.32 \%$ and MMAD of $1.70 \pm 0.03 \mu \mathrm{m}$ ) indicate deposition in the respirable airways i.e. the bronchial-alveolar region of the lungs, ideal for antigen uptake by DCs. Moreover, PGA-co-PDL NPs when co-incubated with DCs showed internalization within $1 \mathrm{~h}$. Further investigations would focus on determining the immunogenicity of the released PspA4Pro in vivo.

\section{Acknowledgements}

Iman M. Alfagih would like to acknowledge the grant from the "Research Centre of the Centre for Female Scientific and Medical Colleges", Deanship of Scientific Research, King Saud University. Douglas B. Figueiredo received a scholarship from Sao Paulo Research Foundation (FAPESP ${ }^{\circ}$ 2012/04858-7). Viviane M. Gonçalves and Eliane N. Miyaji received a grant from FAPESP $(2015 / 06255-6)$

\section{References}

Al-fagih, I.M., Alanazi, F.K., Hutcheon, G.A., Saleem, I.Y., 2011. Recent Advances Using Supercritical Fluid Techniques for Pulmonary Administration of Macromolecules via Dry Powder Formulations. Drug Deliv. Lett. 1, 128-134.

Anish, C., Upadhyay, A.K., Sehgal, D., Panda, A.K., 2014. Influences of process and formulation parameters on powder flow properties and immunogenicity of spray dried polymer particles entrapping recombinant pneumococcal surface protein A. Int. J. Pharm. 466, 198210.

Blank, F., Stumbles, P., von Garnier, C., 2011. Opportunities and challenges of the pulmonary route for vaccination. Expert Opin. Drug Deliv. 8, 547-563.

Bogaert, D., Hermans, P.W., Adrian, P.V., Rumke, H.C., de Groot, R., 2004. Pneumococcal vaccines: an update on current strategies. Vaccine 22, 2209-2220.

Briles, D.E., Ades, E., Paton, J.C., Sampson, J.S., Carlone, G.M., Huebner, R.C., Virolainen, A., Swiatlo, E., Hollingshead, S.K., 2000a. Intranasal immunization of mice with a mixture of the pneumococcal proteins PsaA and PspA is highly protective against nasopharyngeal carriage of Streptococcus pneumoniae. Infect. Immun. 68, 796-800.

Briles, D.E., Hollingshead, S.K., King, J., Swift, A., Braun, P.A., Park, M.K., Ferguson, L.M., Nahm, M.H., Nabors, G.S., 2000b. Immunization of humans with recombinant pneumococcal surface protein A (rPspA) elicits antibodies that passively protect mice from fatal infection with 
Please cite this article as: Kunda, Nitesh K., Alfagih, Iman M., Miyaji, Eliane N.,Figueiredo, Douglas B., Gonc,alves, Viviane M., Ferreira, Daniela M., Dennison, Sarah R., Somavarapu, Satyanarayana, Hutcheon, Gillian A., Saleem, Imran Y., Pulmonary Dry Powder Vaccine of Pneumococcal Antigen Loaded Nanoparticles.International Journal of Pharmaceutics http://dx.doi.org/10.1016/j.ijpharm.2015.09.034

Streptococcus pneumoniae bearing heterologous PspA. J. Infect. Dis. 182, 1694-1701.

Brito, L.A., Singh, M., 2011. Acceptable levels of endotoxin in vaccine formulations during preclinical research. J. Pharm. Sci. 100, 34-37.

Carrillo-Conde, B., Song, E.H., Chavez-Santoscoy, A., Phanse, Y., Ramer-Tait, A.E., Pohl, N.L., Wannemuehler, M.J., Bellaire, B.H., Narasimhan, B., 2011. Mannose-functionalized "pathogen-like" polyanhydride nanoparticles target C-type lectin receptors on dendritic cells. Mol. Pharm. 8, 1877-1886.

Carvalho, R.J., Cabrera-Crespo, J., Tanizaki, M.M., Goncalves, V.M., 2012. Development of production and purification processes of recombinant fragment of pneumococcal surface protein A in Escherichia coli using different carbon sources and chromatography sequences. Appl. Microbiol. Biotechnol. 94, 683-694.

Couvreur, P., Vauthier, C., 2006. Nanotechnology: intelligent design to treat complex disease. Pharm. Res. 23, 1417-1450.

Cruz, L.J., Tacken, P.J., Pots, J.M., Torensma, R., Buschow, S.I., Figdor, C.G., 2012. Comparison of antibodies and carbohydrates to target vaccines to human dendritic cells via DC-SIGN. Biomaterials 33, 4229-4239.

Foged, C., Brodin, B., Frokjaer, S., Sundblad, A., 2005. Particle size and surface charge affect particle uptake by human dendritic cells in an in vitro model. Int. J. Pharm. 298, 315-322. Gamvrellis, A., Leong, D., Hanley, J.C., Xiang, S.D., Mottram, P., Plebanski, M., 2004. Vaccines that facilitate antigen entry into dendritic cells. Immunol. Cell Biol. 82, 506-516. Ghotbi, Z., Haddadi, A., Hamdy, S., Hung, R.W., Samuel, J., Lavasanifar, A., 2011. Active targeting of dendritic cells with mannan-decorated PLGA nanoparticles. J. Drug Target. 19, 281-292.

Ginsburg, A.S., Nahm, M.H., Khambaty, F.M., Alderson, M.R., 2012. Issues and challenges in the development of pneumococcal protein vaccines. Expert Rev. Vaccines 11, 279-285. Gordon, S., Saupe, A., McBurney, W., Rades, T., Hook, S., 2008. Comparison of chitosan nanoparticles and chitosan hydrogels for vaccine delivery. J. Pharm. Pharmacol. 60, 15911600.

Haughney, S.L., Petersen, L.K., Schoofs, A.D., Ramer-Tait, A.E., King, J.D., Briles, D.E., Wannemuehler, M.J., Narasimhan, B., 2013. Retention of structure, antigenicity, and biological function of pneumococcal surface protein $\mathrm{A}(\mathrm{PspA})$ released from polyanhydride nanoparticles. Acta. Biomater. 9, 8262-8271. 
Please cite this article as: Kunda, Nitesh K., Alfagih, Iman M., Miyaji, Eliane N.,Figueiredo, Douglas B., Gonc salves, Viviane M., Ferreira, Daniela M., Dennison, Sarah R., Somavarapu, Satyanarayana, Hutcheon, Gillian A., Saleem, Imran Y., Pulmonary Dry Powder Vaccine of Pneumococcal Antigen Loaded Nanoparticles.International Journal of Pharmaceutics http://dx.doi.org/10.1016/j.ijpharm.2015.09.034

Henzler Wildman, K.A., Lee, D.K., Ramamoorthy, A., 2003. Mechanism of lipid bilayer disruption by the human antimicrobial peptide, LL-37. Biochemistry 42, 6545-6558.

Hicks, L.A., Harrison, L.H., Flannery, B., Hadler, J.L., Schaffner, W., Craig, A.S., Jackson, D., Thomas, A., Beall, B., Lynfield, R., Reingold, A., Farley, M.M., Whitney, C.G., 2007. Incidence of Pneumococcal Disease Due to Non-Pneumococcal Conjugate Vaccine (PCV7) Serotypes in the United States during the Era of Widespread PCV7 Vaccination, 1998-2004. J. Infect. Dis. 196, 1346-1354.

Horta, A.C., Sargo, C.R., da Silva, A.J., de Carvalho Gonzaga, M., Dos Santos, M.P., Goncalves, V.M., Zangirolami, T.C., de Campos Giordano, R., 2012. Intensification of high cell-density cultivations of $\mathrm{rE}$. coli for production of S. pneumoniae antigenic surface protein, PspA3, using model-based adaptive control. Bioprocess Biosyst. Eng. 35, 1269-1280. Horta, A.C.L., Silva, A.J., Sargo, C.R., Velez, A.M., Gonzaga, M.C., Giordano, R.C., Gonçalves, V.M., Zangirolami, T.C., 2014. A supervision and control tool based on artificial intelligence for high cell density cultivations. Braz. J. Chem. Eng. 31, 457-468. Jambo, K.C., Sepako, E., Heyderman, R.S., Gordon, S.B., 2010. Potential role for mucosally active vaccines against pneumococcal pneumonia. Trends Microbiol. 18, 81-89.

Joshi, V.B., Geary, S.M., Salem, A.K., 2013. Biodegradable particles as vaccine delivery systems: size matters. AAPS. J. 15, 85-94.

Kadioglu, A., Weiser, J.N., Paton, J.C., Andrew, P.W., 2008. The role of Streptococcus pneumoniae virulence factors in host respiratory colonization and disease. Nat. Rev. Microbiol. 6, 288-301.

Karagouni, E., Kammona, O., Margaroni, M., Kotti, K., Karageorgiou, V., Gaitanaki, C., Kiparissides, C., 2013. Uptake of BSA-FITC Loaded PLGA Nanoparticles by Bone MarrowDerived Dendritic Cells Induces Maturation But Not IL-12 or IL-10 Production. Nanosci. Nanotechnol. Lett. 5, 498-504.

Kong, I.G., Sato, A., Yuki, Y., Nochi, T., Takahashi, H., Sawada, S., Mejima, M., Kurokawa, S., Okada, K., Sato, S., Briles, D.E., Kunisawa, J., Inoue, Y., Yamamoto, M., Akiyoshi, K., Kiyono, H., 2013. Nanogel-based PspA intranasal vaccine prevents invasive disease and nasal colonization by Streptococcus pneumoniae. Infect. Immun. 81, 1625-1634.

Koppolu, B., Zaharoff, D.A., 2013. The effect of antigen encapsulation in chitosan particles on uptake, activation and presentation by antigen presenting cells. Biomaterials 34, 2359-2369.

Kunda, N.K., Alfagih, I.M., Dennison, S.R., Tawfeek, H.M., Somavarapu, S., Hutcheon, G.A., 
Please cite this article as: Kunda, Nitesh K., Alfagih, Iman M., Miyaji, Eliane N.,Figueiredo, Douglas B., Gonc,alves, Viviane M., Ferreira, Daniela M., Dennison, Sarah R., Somavarapu, Satyanarayana, Hutcheon, Gillian A., Saleem, Imran Y., Pulmonary Dry Powder Vaccine of Pneumococcal Antigen Loaded Nanoparticles.International Journal of Pharmaceutics http://dx.doi.org/10.1016/j.ijpharm.2015.09.034

Saleem, I.Y., 2015. Bovine serum albumin adsorbed PGA-co-PDL nanocarriers for vaccine delivery via dry powder inhalation. Pharm. Res. 32, 1341-1353.

Kunda, N.K., Somavarapu, S., Gordon, S.B., Hutcheon, G.A., Saleem, I.Y., 2013.

Nanocarriers targeting dendritic cells for pulmonary vaccine delivery. Pharm. Res. 30, 325341.

Kwon, Y.J., Standley, S.M., Goh, S.L., Frechet, J.M., 2005. Enhanced antigen presentation and immunostimulation of dendritic cells using acid-degradable cationic nanoparticles. J. Control. Release 105, 199-212.

Menzel, M., Muellinger, B., Weber, N., Haeussinger, K., Ziegler-Heitbrock, L., 2005. Inhalative vaccination with pneumococcal polysaccharide in healthy volunteers. Vaccine 23, 5113-5119. Meyer, P., Menzel, M., Muellinger, B., Weber, N., Haeussinger, K., Ziegler-Heitbrock, L., 2006. Inhalative vaccination with pneumococcal polysaccharide in patients with chronic obstructive pulmonary disease. Vaccine $24,5832-5838$.

Miyaji, E.N., Oliveira, M.L., Carvalho, E., Ho, P.L., 2013. Serotype-independent pneumococcal vaccines. Cell Mol. Life Sci. 70, 3303-3326.

Moreno, A.T., Oliveira, M.L., Ferreira, D.M., Ho, P.L., Darrieux, M., Leite, L.C., Ferreira, J.M., Jr., Pimenta, F.C., Andrade, A.L., Miyaji, E.N., 2010. Immunization of mice with single PspA fragments induces antibodies capable of mediating complement deposition on different pneumococcal strains and cross-protection. Clin. Vaccine Immunol. 17, 439-446.

Nabors, G.S., Braun, P.A., Herrmann, D.J., Heise, M.L., Pyle, D.J., Gravenstein, S., Schilling, M., Ferguson, L.M., Hollingshead, S.K., Briles, D.E., Becker, R.S., 2000. Immunization of healthy adults with a single recombinant pneumococcal surface protein A (PspA) variant stimulates broadly cross-reactive antibodies to heterologous PspA molecules. Vaccine 18, 1743-1754.

O'Hagan, D.T., 2001. New Generation Vaccine Adjuvants, eLS. John Wiley \& Sons, Ltd. Ogunniyi, A.D., Grabowicz, M., Briles, D.E., Cook, J., Paton, J.C., 2007. Development of a vaccine against invasive pneumococcal disease based on combinations of virulence proteins of Streptococcus pneumoniae. Infect. Immun. 75, 350-357.

Ogunniyi, A.D., Woodrow, M.C., Poolman, J.T., Paton, J.C., 2001. Protection against Streptococcus pneumoniae elicited by immunization with pneumolysin and CbpA. Infect. Immun. 69, 5997-6003.

Ren, B., McCrory, M.A., Pass, C., Bullard, D.C., Ballantyne, C.M., Xu, Y., Briles, D.E., Szalai, 
Please cite this article as: Kunda, Nitesh K., Alfagih, Iman M., Miyaji, Eliane N.,Figueiredo, Douglas B., Gonc,alves, Viviane M., Ferreira, Daniela M., Dennison, Sarah R., Somavarapu, Satyanarayana, Hutcheon, Gillian A., Saleem, Imran Y., Pulmonary Dry Powder Vaccine of Pneumococcal Antigen Loaded Nanoparticles.International Journal of Pharmaceutics http://dx.doi.org/10.1016/j.ijpharm.2015.09.034

A.J., 2004a. The virulence function of Streptococcus pneumoniae surface protein A involves inhibition of complement activation and impairment of complement receptor-mediated protection. J. Immunol. 173, 7506-7512.

Ren, B., Szalai, A.J., Hollingshead, S.K., Briles, D.E., 2004b. Effects of PspA and antibodies to PspA on activation and deposition of complement on the pneumococcal surface. Infect. Immun. 72, 114-122.

Saleem, I.Y., Vordermeier, M., Barralet, J.E., Coombes, A.G., 2005. Improving peptide-based assays to differentiate between vaccination and Mycobacterium bovis infection in cattle using nanoparticle carriers for adsorbed antigens. J. Control. Release 102, 551-561.

Seville, P.C., Learoyd, T.P., Li, H.Y., Williamson, I.J., Birchall, J.C., 2007. Amino acid-modified spray-dried powders with enhanced aerosolisation properties for pulmonary drug delivery. Powder Technol. 178, 40-50.

Shaper, M., Hollingshead, S.K., Benjamin, W.H., Jr., Briles, D.E., 2004. PspA protects Streptococcus pneumoniae from killing by apolactoferrin, and antibody to PspA enhances killing of pneumococci by apolactoferrin [corrected]. Infect. Immun. 72, 5031-5040.

Singleton, R.J., Hennessy, T.W., Bulkow, L.R., Hammitt, L.L., Zulz, T., Hurlburt, D.A., Butler, J.C., Rudolph, K., Parkinson, A., 2007. Invasive pneumococcal disease caused by nonvaccine serotypes among alaska native children with high levels of 7-valent pneumococcal conjugate vaccine coverage. JAMA 297, 1784-1792.

Sou, T., Kaminskas, L.M., Nguyen, T.H., Carlberg, R., McIntosh, M.P., Morton, D.A., 2013. The effect of amino acid excipients on morphology and solid-state properties of multicomponent spray-dried formulations for pulmonary delivery of biomacromolecules. Eur. J.

Pharm. Biopharm. 83, 234-243.

Stolnik, S., Daudali, B., Arien, A., Whetstone, J., Heald, C.R., Garnett, M.C., Davis, S.S., Illum, L., 2001. The effect of surface coverage and conformation of poly(ethylene oxide) (PEO) chains of poloxamer 407 on the biological fate of model colloidal drug carriers. Biochim. Biophys. Acta. 1, 261-279.

Tawfeek, H., Khidr, S., Samy, E., Ahmed, S., Murphy, M., Mohammed, A., Shabir, A., Hutcheon, G., Saleem, I., 2011. Poly(glycerol adipate-co-omega-pentadecalactone) spraydried microparticles as sustained release carriers for pulmonary delivery. Pharm. Res. 28, 2086-2097.

Tawfeek, H.M., Evans, A.R., Iftikhar, A., Mohammed, A.R., Shabir, A., Somavarapu, S., 
Please cite this article as: Kunda, Nitesh K., Alfagih, Iman M., Miyaji, Eliane N.,Figueiredo, Douglas B., Gonc,alves, Viviane M., Ferreira, Daniela M., Dennison, Sarah R., Somavarapu, Satyanarayana, Hutcheon, Gillian A., Saleem, Imran Y., Pulmonary Dry Powder Vaccine of Pneumococcal Antigen Loaded Nanoparticles.International Journal of Pharmaceutics http://dx.doi.org/10.1016/j.ijpharm.2015.09.034

Hutcheon, G.A., Saleem, I.Y., 2013. Dry powder inhalation of macromolecules using novel PEG-co-polyester microparticle carriers. Int. J. Pharm. 441, 611-619.

Thompson, C.J., Hansford, D., Higgins, S., Hutcheon, G.A., Rostron, C., Munday, D.L., 2006. Enzymatic synthesis and evaluation of new novel omega-pentadecalactone polymers for the production of biodegradable microspheres. J. Microencapsul. 23, 213-226.

Vadesilho, C.F., Ferreira, D.M., Moreno, A.T., Chavez-Olortegui, C., Machado de Avila, R.A., Oliveira, M.L., Ho, P.L., Miyaji, E.N., 2012. Characterization of the antibody response elicited by immunization with pneumococcal surface protein A (PspA) as recombinant protein or DNA vaccine and analysis of protection against an intranasal lethal challenge with Streptococcus pneumoniae. Microb. Pathog. 53, 243-249.

Walker, C.L., Rudan, I., Liu, L., Nair, H., Theodoratou, E., Bhutta, Z.A., O'Brien, K.L., Campbell, H., Black, R.E., 2013. Global burden of childhood pneumonia and diarrhoea. Lancet $381,1405-1416$.

Wang, S., Curtiss III, R., 2014. Development of Streptococcus pneumoniae Vaccines Using Live Vectors. Vaccines 2, 49-88.

Wardlaw, T., Salama, P., Johansson, E.W., Mason, E., 2006. Pneumonia: the leading killer of children. Lancet 368, 1048-1050.

Whitmore, L., Woollett, B., Miles, A.J., Janes, R.W., Wallace, B.A., 2010. The protein circular dichroism data bank, a Web-based site for access to circular dichroism spectroscopic data.

Structure 18, 1267-1269.

Xu, P., Gullotti, E., Tong, L., Highley, C.B., Errabelli, D.R., Hasan, T., Cheng, J.X., Kohane, D.S., Yeo, Y., 2009. Intracellular drug delivery by poly(lactic-co-glycolic acid) nanoparticles, revisited. Mol. Pharm. 6, 190-201.

Yamamoto, M., Briles, D.E., Yamamoto, S., Ohmura, M., Kiyono, H., McGhee, J.R., 1998. A nontoxic adjuvant for mucosal immunity to pneumococcal surface protein A. J. Immunol. 161, 4115-4121.

Zhao, L., Seth, A., Wibowo, N., Zhao, C.X., Mitter, N., Yu, C., Middelberg, A.P., 2014.

Nanoparticle vaccines. Vaccine 32, 327-337. 